Nicholas Van Hear, Centre on Migration, Policy and Society (COMPAS), University of Oxford

\title{
Reconsidering migration and class
}

\begin{abstract}
While once a mainstay of social science, class has lately been eclipsed in much of migration studies by consideration of other forms of social difference, affinity and allegiance such as ethnicity, gender, generation and lately religion. This article puts the case for renewing attention on the part class plays in shaping migration - particularly who is able to move and to where. It argues that the form of migration and ultimately its outcomes are shaped by the resources that would-be migrants can muster, and that in turn the capacity to mobilise such resources is largely determined by socioeconomic background or class. Drawing on Bourdieu, class can be conceived in terms of the disposal of different forms of capital -- economic, social and cultural. Having access to combinations of such capital shapes the routes and channels migrants can follow, the destinations they can reach, and their life chances after migration. The article first reflects briefly on ideas of class in social science and sketches treatment of mobility in the migration literature, before considering the ways in which class, mobility and immobility shape each other. The article concludes by considering the interplay between migration, class and collective action among those who move and those who stay, against the background of broader currents of social change and transformation.
\end{abstract}

Accepted for publication in International Migration Review, 48, 2014 


\section{Introduction}

'I went as far as my money would take me' a Ghanaian returnee interviewed in the late 1990s told me. He was a would-be asylum seeker who wound up in Lebanon, not because he particularly wanted to go there, but because this was the destination he could reach with the money and connections he had at his disposal. Like others, he had hoped to use Lebanon as a stepping stone to a more prosperous destination, but ran out of money and had to go back to Ghana (Van Hear 2004, 2006). The case illustrates the simple point developed in this article: that patterns and outcomes of migration are shaped by the resources migrants can mobilise, and those resources are largely determined by socio-economic background. The Ghanaian migrant's words seemed to illustrate well the observation that struck me at the time - that different people reach different destinations, shaped largely though not entirely by endowments of resources, or class for short. Conversations with many migrants since have more than borne out this observation.

Yet even though class or socio-economic differentiation used to be mainstays of social science, they have arguably been underplayed in much of migration studies in recent years. Forms of social difference, affinity or allegiance such as ethnicity, gender, generation and lately religion have rather become the key concerns. Though class is making a comeback in social science more widely (Bottero 2004; Savage et al 2013), this is less evident in migration studies. Where class, socio-economic inequality or social mobility have been considered, it has usually been with respect to migration outcomes in host or destination countries -- that is to say, in what happens after migration (Castles and Kosack 1973; Cohen 1987; Portes 2010; Oliver and O'Reilly 2010; Card and Raphael 2013; Pero 2014). The way class shapes the migration process itself - by which is meant migrant decisionmaking, routes, channels and destinations -- has received rather less attention. It is this gap that the article seeks to address.

This article puts the case then for a rehabilitation of class in the study of migration -- particularly in terms of who is able to move and to where. It argues that the form of migration and its outcomes are shaped by the resources - economic or network-based -- that would-be migrants can muster. The capacity to mobilise those resources is largely determined by socio-economic background or class, which, drawing on Bourdieu, can be conceived in terms of the disposal of different amounts and forms of capital -- economic, social, cultural, symbolic, and so on. Holding combinations of such capital shapes the routes would-be migrants can take, the channels they can follow, the destinations they can reach, and their life chances afterwards. 
The article proceeds by tracing different concepts of class and mobility that have unfolded in recent years, and then draws together these two tracks of thinking. It first reflects briefly on the consideration of class in social science, and then reviews treatment of mobility and immobility in the migration and cognate literatures. It then considers the intersection between class and mobility and explores some of the challenges thrown up by this intersection. The article finally considers the interplay between migration, class and collective action among those who leave and those who stay, in the context of broader currents of social change and transformation. The approach of the article is to draw together and build on some of the debates in migration and mobility studies over the last two or three decades. It makes no claim to present a systematic synthesis of any of the broad themes addressed, but reflects some of the approaches that I have found helpful in thinking about migration. This has involved revisiting some of the past literature on these issues - spanning the half century or more of the life of the International Migration Review - to see to see if it can help us to understand the current migration scene.

\section{Considering class: from Marx and Weber to Castoriadis and Bourdieu}

What is class? Is it a useful way of looking things, a useful mode of analysis -- in social science generally and in migration studies in particular?

Class was of course an organising principle of society for the 'founding fathers' of social science Marx, Weber and to a lesser extent Durkheim. As is well known, for Marx class was shaped by the relationship to the ownership of the means of production. Weber distinguished between class as a position in relation to economic life, and status or standing in relation to position in the wider community or society, incorporating the idea of social honour or prestige. Broadly speaking, variants and refinements of these notions shaped social science thinking until post-modernism and the 'cultural turn' came to dominate social science from the 1990s. Putting it crudely, post-modernist analysis (rightly) portrayed contemporary society as fragmenting and social relations as atomising, including many traditional allegiances like class (Bottero 2004). Power was certainly still central in much of this mode of analysis-notably in the notion of 'difference'. But the view in this strand of thinking came to be that class was no longer relevant and class analysis was no longer useful as a way of understanding society. Other identifications and allegiances were much more significant, it was argued, the more so as the organising logic of society had moved from production to consumption - particularly in the global north, but increasingly also elsewhere in the world. Much of this analysis did resonate with what was observable in society, but arguably the class baby was drowned in the identity bathwater. 
Other strands of analysis had meanwhile continued to emphasise the importance of class, while critically modifying the Marxist and Weberian notions of class that broadly held sway in social science in the 1960s and 1970s. I draw out two approaches here that I find helpful in thinking about migration and class: both come from the current of French social theorists that has been influential in social science since the 1970s.

The Greek-French philosopher and social critic Cornelius Castoriadis, rather less known than his influential contemporary Foucault ${ }^{1}$, refined the notion of class through analysis of what he called the 'crisis of modern society' in terms of authority relations in society at large. For him, the key dimension was control rather than ownership of the means of production, distribution and exchange, and the key division was between those in society who give orders and those who carry them out:

For classical Marxism the division of society was between capitalists, who owned the means of production, and property-less proletarians. Today the division must be seen as between order-givers (dirigéants) and order-takers (exécutants). (Castoriadis 1964: 6)

The order-giver/order-taker division was the basic principle of social organisation in what Castoriadis called 'bureaucratic capitalism', which he saw as the predominant form of capitalism before the neoliberal turn from the late 1970s. While perhaps commonplace now, conceiving division in society in terms of authority relations was an advance on the orthodox Marxist view of class, particularly in the light of the post-war changes in society in the developed world. But although Castoriadis emphasised the importance of authority relations in society as a whole, his order-giver/order-taker division still upheld the primacy of production -- or rather control of the means of production. This was despite his prescient recognition -- influenced by the contemporaneous Situationist critique of the 'commodification' of everyday life -- that consumption was taking over from production as the driving force structuring society. Nevertheless, conceiving class in terms of authority relations was at the time a step forward and still retains its utility as a framework for considering class.

While the contribution of Castoriadis to advancing understanding of class remains underplayed, other concepts of class have gained greater purchase. Currently among the most popular renditions of class for social scientists, Bourdieu's analysis deftly drew critically upon Marx, Weber and Durkheim to craft a convincing framework for understanding class (Wacquant 2013). As is well

\footnotetext{
${ }^{1}$ Castoriadis was one of the lesser known of the influential current of leftist French intellectuals that included the neo-Marxist anthropologists, Foucault, Derrida and Bourdieu -- all men, all born within ten years of each other (from 1922-1930), and now all dead.
} 
known, Bourdieu's conceptualisation involved understanding endowments of different forms and amounts of capital:

(F)irstly, economic capital, in various kinds; secondly, cultural capital or better, informational capital, again in various kinds; and thirdly two forms of capital that are very strongly correlated, social capital, which consists of resources based on connections and group membership, and symbolic capital, which is the form the different types of capital take once they are perceived and recognized as legitimate (Bourdieu 1987: 4)

Economic capital was seen as command of economic resources and assets, while cultural capital was a given person's collection of knowledge, tastes, skills, education and other competencies.

Elaborating the notion of social capital, Bourdieu suggested that it was 'the aggregate of the actual or potential resources which are linked to the possession of a durable network'. The amount of social capital possessed by a given agent was dependent on the size of the network of connections that could be mobilised and on the volume of capital held by the whole set of agents with whom there were connections (Bourdieu 1986: 248-249). Bourdieu noted that the various forms of capital were unevenly distributed:

Two individuals endowed with an equivalent overall capital can differ ...in that one holds a lot of economic capital and little cultural capital while the other has little economic capital and large cultural assets (Bourdieu and Wacquant 1992: 99).

Moreover he underlined that one form of capital could be converted into another (Bourdieu 1986; Bourdieu and Wacquant 1992). This feature of Bourdieu's notion of capital -- that it could be accumulated, transferred and converted -- is most useful for migration studies, because it helps to explain how someone with little economic capital may be able to convert their social capital (via networks for example) so as to be able to migrate or to advance their life projects after migration: this fungible quality of class in the context of migration is explored further below.

As important as its theoretical elegance is the fact that Bourdieu's approach is a useable framework. His formulation has of course inspired much that came later in social science consideration of social difference: a recent example is the British Class Survey (Savage et al 2013). As the publicity for the authors' 'new model of social class' noted, 'We devised a new way of measuring class, which doesn't define class just by the job that you do, but by the different kinds of economic, cultural and social resources or 'capitals' that people possess' (BBC Science 3 April 2013, accessed 2708 13).

While reflecting Bourdieu's subtle appreciation of class, this is refreshingly pragmatic. However there is still something missing, and that is the sense of classes as collectivities, as opposed to 
aggregate collections of individuals who possess different 'capitals'. There is an analytical need for some indication of wider identification or connection: not necessarily conscious collectivities as in the notion of 'class for itself', but at least 'actually-existing' collectivities as in the idea of 'class in itself' - class as a 'social fact'. The sense is needed of the position of a given class in hierarchical society where power and wealth are distributed unevenly. In this respect, it might be instructive to weave together something like Castoriadis' notion of class based on authority and power relations on the division between order-givers and order-takers -- with Bourdieu's notion of different endowments of capital. Inspired by the insights of these two thinkers, the prize sought is an interweaving of the material features of social relations embodied in these approaches with key insights on forms of identification that the 'cultural turn' has provided. An attempt at such an approach is returned to later in this paper.

\section{The unfolding of migration studies: the transnationalism and mobilities 'turns'}

Having briefly considered some notions of class in social science, the paper turns to strands of thinking on migration, mobility and immobility, tracking some of the various so-called 'turns' that have unfolded in the field of migration studies.

The review of conceptual approaches to migration set out by Douglas Massey and his colleagues two decades ago remains one of the starting points for mapping the way in which migration studies has unfolded (see King 2012 for a more recent synthesis). As is well known, in their book Worlds in Motion (1998), the outcome of their endeavour which began in the early 1990s (Massey et al 1993), Massey and his colleagues traced approaches to the inception and perpetuation of migration. Their synthesis of migration theories pointed to how explanations of the initiation of migration could be found in a number of approaches. Drawing on cost-benefit analysis, neo-classical approaches located the drivers of migration in differences in income levels between places, while what became known as the new economics of (labour) migration pointed to decision-making not just by individuals, but by households, with the object not just of maximising income, but of spreading risk (Stark 1991). Segmented labour market theory held that migration was shaped by labour demand in industrialised societies, while variants of historical-structural and world systems theories sought explanations of migration in the unequal distribution of power worldwide through a political economy approach drawing on Marxist analyses. Explanations of the perpetuation of migration could be found in theories about social capital and networks, which pointed to ways in which social connections could be drawn upon in the migration process, while the notion of cumulative causation highlighted the manner in which each act of migration altered the social context in which 
subsequent migration decisions were made, often making additional movement more likely (Massey et al 1998). Implicitly if not explicitly, socio-economic differentiation played a role in most if not all of these approaches to the initiation and perpetuation of migration, including the selection of those most likely to migrate and those prone to continue to do so (Orrenius and Zavodny 2005).

The diversity of approaches to understanding migration was arguably both a strength and a weakness. As Massey and his colleagues remarked

At present, there is no single theory widely accepted by social scientists to account for the emergence and perpetuation of international migration throughout the world, only a fragmented set of theories that have developed largely in isolation from one another, sometimes but not always segmented by disciplinary boundaries (Massey et al 1998: 17). The appeal of a grand theory of migration remains limited in the research community (Castles 2010), but two analytical strands that could arguably make a claim to over-arching conceptual approaches to migration have been the transnationalism approach and the so-called 'mobilities turn'. In different ways both of these strands of thinking feature the relationship between those who leave and those who stay behind in the community of origin - or more broadly the relationship between mobility and immobility.

Despite claims to novelty, consideration of both transnationalism and the relationship between mobility and immobility has a long pedigree. Taking just the literature over the last two decades, we may start (perhaps arbitrarily) with Liisa Malkki's work in the early 1990s in which she aimed at 'normalising' mobility, as a counterpoint to the assumption that rootedness or being in place was the standard state of affairs and that movement was aberrant (Malkki 1992). She used the terms 'sedentary metaphysics', 'sedentary bias' and 'sedentarist common sense' to characterise such assumptions in social science generally and in refugee and migration studies in particular - a critique now quite commonplace in the literature.

From a different angle, what might be called the 'North European school' of migration studies which emerged in the mid 1990s turned the more usual question 'why do people migrate?' on its head, asking instead 'why do so few people migrate and why do so many stay put?' (Hammar et al 1997). The puzzle was the coexistence of 'massive relative immobility' - the fact that most people do not move -- with 'widespread mass migration' from a limited number of places: why were there so few migrants from most places and so many migrants from only a few places? (Faist 2000). Carling 
(2002) later refined this approach by underlining that we live in an age of 'involuntary immobility' as much as in an 'age of migration'.

My own work also drew attention to 'people who go and people who stay', while noting the importance of compulsion and choice in moving or staying put (Van Hear 1998). In disaggregating migratory movements, five dimensions or components of migration could be identified, involving degrees of force and choice: moving out (outward movement, out-migration or emigration); coming in (inward movement or immigration); moving on (onward movement); moving back (going home, return, repatriation); and staying put (encompassing 'immobility', roots, moorings, stayers, the left behind). It was suggested that someone might experience all of these permutations of movement and non-movement over the course of a lifetime and that they could each feature different permutations of compulsion and choice: someone may be forced to move out but have some say in where they go or move on to; conversely moving out may be a choice, but returning may be compulsory, as with some kinds of repatriation. 'Staying put', or immobility, was one of the five dimensions, and the distinction was made between 'stayers by choice' and 'stayers of necessity' (Van Hear 1998).

This approach was located within the burgeoning literature on transnationalism and diaspora that emerged from the mid 1990s (Glick Schiller et al 1992, Cohen 1997/2008). Again the approach was by no means entirely new (Portes et al 1999), but the connected notions of transnationalism and diaspora underlined the idea that migrants no longer made a sharp break with their homelands (if indeed they ever did), nor was most migration a simple unilinear movement. Rather, links with the homeland continued to be salient, connections which were maintained from afar through remittances and other forms of transfer and exchange, or through return and circular migration. There was thus insistence on the significance of continuing connections between those who had left and those who had stayed, and the suggestion that they were occupying 'transnational social spaces' (Faist 2000), encompassed in a 'transnational social field' (Levitt and Glick Schiller 2004), and engaged in 'transnational living' (Guarnizo 2003). In the case of diaspora, the transnational linkages were not only between the host and home societies, but also with other societies in which diaspora members were located.

Meanwhile, somewhat separately from these strands of thinking, the so-called 'new mobilities paradigm' was gaining currency (Urry 2000, 2007; Sheller and Urry 2006). Highlighting the phenomenon of 'intersecting mobilities' (Sheller and Urry 2006: 207), this approach set migration of 
people in the broader context of diverse kinds of movement - of money, ideas, goods and things and took hold in the 2000s, becoming in some ways an alternative to migration studies or even arguably subsuming them. Again, mobility was seen as an organising principle of society neglected by 'sedentarist' or 'static' social science (Sheller and Urry 2006: 208).

It seems that a new paradigm is being formed within the social sciences, the 'new mobilities' paradigm...Social science has largely ignored or trivialised the importance of the systematic movements of people for work and family life, for leisure and pleasure, and for politics and protest. The paradigm challenges the way in which much social science research has been 'a-mobile' (ibid: 208).

While this approach has reinvigorated thinking about movement in novel ways - not least by thinking through the implications of 'intersecting mobilities' -- some of this literature perhaps celebrated mobility uncritically, to the neglect of immobility as its counterpart. This led some critics to complain that the mobilities paradigm left little room 'for a dialectical understanding of the dichotomy mobility/immobility as mutually constructed poles' (Franquesa 2011: 1016).

Over the last two decades or more then, the unfolding of migration studies and the cognate study of mobilities have led to recognition that mobility and immobility need to be considered in conjunction with one another, with examination needed of both movers and stayers, mobility and moorings. So in a way since the early 1990s we have moved full circle - from 'normalising mobility', to somewhat uncritically celebrating mobility, to acknowledgment of transnational relations between those who leave and those who stay, and to re-discovering 'immobility' or 'staying put' as a phenomenon of significance that needs to be considered alongside mobility.

\section{Perspectives on mobility and class: different endowments, different movement}

Having briefly considered these two strands of thinking - on class and on mobility - the paper turns to those who have considered class and mobility in conjunction with one another, combining the two perspectives and exploring how they play into one another.

Again we can go back to the early 1990s as a (somewhat arbitrary) point of departure. Writing at roughly the same time as Malkki, though from a rather different starting point, Doreen Massey argued that

...different social groups and different individuals are placed in very distinct ways in relation to ... flows and interconnections. This point concerns not merely the issue of who moves and who doesn't...; it is also about power in relation to the flows and the movement. 
Different social groups have different relationships to this...mobility: some are more in charge of it than others; some initiate flows and movement, others don't; some are more on the receiving end of it than others; some are effectively imprisoned by it. (Massey 1993: 61) This statement captured succinctly the class and power relations involved in migration and mobility. The observation was part of what Massey termed 'power geometry', her elaboration of the notion of 'time-space compression' developed by Harvey (1989) with its connotation of the geographical 'stretching-out' of social relations, particularly those involving movement and communication across space. Drawing comparison between the circulation of money and the circulation of people, and referring to forced migration, Hyndman later made a similar point:

Those with money can take advantage of time-space compression. Those who are uprooted from their homes and forced to flee their country with few resources experience migration in a very different way (Hyndman 2000: 37).

In similar vein, exploring 'the politics of mobility', Cresswell later characterised mobility as one of the major resources of $21^{\text {st }}$ century life, and it was 'the differential distribution of this resource that produces some of the starkest differences today' (Cresswell 2010: 22). He explored six dimensions of mobility -- motive force, speed, rhythm, route, experience and friction -- which can play out differently according to one's access to the 'resource' of mobility. Making a similar argument, Sheller and Urry (2006: 207) utilised the metaphor of mobility in 'fast and slow lanes' shaped by access to resources and power. They pointed to 'the proliferation of places, technologies and 'gates' that enhance the mobilities of some while reinforcing the immobilities of others...' (ibid: 213), and the ways such technologies are 'producing a 'kinetic elite' whose ease of mobility differentiates them from the low-speed, low mobility majority' (ibid: 219). In a critical reformulation of the 'mobilities turn', Franquesa (2011) underlined not just the importance of differentiated access to mobility, but also the dialectical relationship between mobility and immobility: 'Power, then, is not so much located in the pole of mobility, as an intrinsic attribute of it, but rather in the capacity to manage the relation between mobility and immobility' (Franquesa 2011: 1028). His point was to emphasise how social and power relations produce both mobility and immobility, and how that shapes the capacity to choose whether to move or stay put.

These conceptual approaches provide some useful pointers to how power relations may be conceived in conditions of mobility. In my own thinking, the capacity to make choices among the five mobility/immobility permutations outlined in the previous section was largely shaped by endowments of capital or 'class'. Each of the five trajectories is shaped by the resources that can be mustered at the time. This is where Bourdieu's notion of class becomes helpful. 
As noted above in the consideration of Bourdieu's notion of disposal of different forms of capital shaping an individual's class position, capital can be acquired, transmitted and converted. Of most relevance for the purposes of this paper is that one form of capital - economic, social, symbolic, cultural, political, and so on - can be converted into another (Bourdieu 1986; Bourdieu and Wacquant 1992). These notions of classes and of different endowments of capital that can be transmitted or converted can be usefully applied to the migration arena. It is now largely accepted that international migration is not typically for the poorest of the poor, but is engaged in by those who can mobilise some level of resources. Put simply, there is a hierarchy of destinations that can be reached by migrants, according to the resources -- economic and network-based -- that they can call upon. As the migration polices of more prosperous and desirable destinations have become more stringent, the main factors which determine the ability to reach them have increasingly become cost and connections, not least as the more affluent destinations attract higher premiums both through official channels of entry and in terms of smugglers' and agents' charges if irregular routes are followed. It follows that access to more prosperous and desirable destinations is limited to better resourced migrants. International migration therefore requires the accumulation or possession of amounts of economic, social, cultural and other forms of capital in various combinations. Navigating what can be termed in aggregate the international migration regime requires different amounts, forms and combinations of capital. For some destinations a certain amount of economic capital may be sufficient. In other cases cultural and social capital may also be required. Thus only those who are endowed with certain volumes of capital in certain compositions or proportions, or who can convert other forms of capital into the required forms in the required compositions, can undertake international migration - to more affluent destinations at least. The capacity for a would-be migrant to navigate the international migration order will be largely shaped by his or her endowments of economic and social capital, or the amount of economic, social and other capital a would-be migrant can call upon, as the experience of the Ghanaian migrant featured at the beginning of this article attests.

Hypothetically then, someone with few financial assets but well-endowed with cultural or social capital might be able to get as far as someone with financial clout but few social connections. Furthermore someone endowed with little economic capital but plentiful social, cultural or symbolic capital may be able to convert the latter forms into the volume of economic capital needed to migrate - for example by drawing on networks to borrow resources to cover the costs of migration. Incidentally, this notion of the conversion of one form of capital into another helps us to understand the 'irrational' expenditure by migrants of remittances and other household resources on 'wasteful' 
social outlays or functions that have so exasperated mainstream development economists and practitioners (Mazzucato et al 2006).

For the purposes of illustration, let me put this in rather crude monetary terms taken from a case I am familiar with. In a conflict setting like that of Sri Lanka, there have been two principal forms of migration that people in conflict-affected areas could undertake - refugee flight and labour migration (there are others too, notably student migration and marriage migration, but for argument's sake we will consider just these two). Both entail outlays by the households of the migrant. But the resources needed for asylum migration (which may include the payment of agents or smugglers) have been about twenty times those needed for labour migration - a ratio that has remained constant for the last 15 or more years. It follows that in conflict settings people from better-endowed households may be able to access asylum routes to affluent countries, while those from less well-off households use labour migration as a means to seek security, make a living and support their families left behind. This can be seen in many communities in war-torn northern Sri Lanka: by and large wealthy families have moved out completely to countries in the affluent global north; less well-endowed households manage to send one or two family members abroad to such countries; and poorer households might be able to generate the resources needed to send a family member to the Middle East to work on short contracts.

Similar patterns can be observed in other migratory settings. The outlays needed to enable household members to migrate have to be set against the anticipated benefits of migration and the obstacles encountered on the way - not least those generated by the international migration regime of increasingly restrictive policies and practices. More resources are needed en route and need to be mobilised or accumulated in the step-wise journeys that it is now well-known migrants often make, as the experience of the Ghanaian migrant mentioned at the outset also shows.

Some refinement of this framework is needed, for it is obviously not the case that all the wellendowed are mobile and the less-endowed are not. As already noted, it is now well established that it is often those with some resources that migrate - rather than the poor, who do not have the resources to do so, or the rich, who can stay put if they wish. What counts is the degree of choice in moving or staying put, reflecting the ways in which power and authority relations come into play. Sometimes, it may be the privileged who can leave while the less endowed are forced to stay, stuck in involuntary immobility. The well-endowed may have the resources to move if they want or need to, while the less endowed have no choice but to stay put because they have insufficient resources 
to move across borders. At other times, while the less-endowed must leave, the privileged may choose to stay. In challenging circumstances, the well-endowed may have the resources to stay put -- for example, the means to bribe combatants on both sides of a conflict that they should be allowed to stay on -- and it may be that the less-endowed have no choice but to move. So in sum the range of conditions includes 'voluntary' mobility or immobility on one hand and forced mobility or immobility on the other, depending on the possibility and degree of exercising agency or choice. The key point is that the choice of whether to move or stay put is shaped by resources or different endowments of capital - class for short.

\section{Mobility, 'class for itself', exit and voice}

So far in this article the relationship between class, mobility and immobility has been considered mainly at the level of the individual and household. As suggested above, for a comprehensive grasp of the relationship between class and mobility, we also need to understand classes as collectivities -as more than aggregates of individuals who possess different 'capitals' or who have a given position in the social power hierarchy. In this final section the relationship between those who move and those who stay is considered from this perspective.

In the Marxist tradition the distinction is often made between 'class in itself' and 'class for itself' 'Class in itself' is seen as a collectivity with certain identifiable attributes and interests in common, while 'class for itself' is regarded as a collectivity that acts in pursuit of those common interests. If we can see elements of 'class in itself' operating in the migration field in terms of shaping the means, routes and destinations of migration, as explored above, are there ways in which 'class for itself' figures on the migration scene? If class helps us to understand how options to move or stay put are shaped at the individual or household level, how do migration and class play out in broader currents of social change and transformation? In the following I explore some ways in which those who lead transnational lives act in collective ways, as featured in the interplay between migration, class and the recent wave of global protest in places as diverse as Egypt, Turkey, Ukraine and Brazil.

Much of this recent wave of protest has been driven by educated but underemployed young people - including many with tertiary education. At the same time, much global migration is drawn from this same socio-economic group, for as argued above, it tends to be those who have some resources - typically through their networks - that undertake international migration. This seems to be the case in the so-called 'global north' as much as in the so-called 'emerging' economies: people in their twenties and thirties in both of these worlds protest and move - and sometimes do both. This

\footnotetext{
${ }^{2}$ Even if Marx did not explicitly make this distinction in these terms (Andrew 1983).
} 
somewhat obvious observation perhaps deserves closer attention than it has received to date: for what is the relationship between burgeoning international migration and the recent explosion of global protest and resistance movements (Mason 2013; Castells 2012, 2013; Graeber 2013; Van Hear 2013)? And does the notion of class help us to understand the social groups that drive both much protest and international migration?

As one commentator on the protests puts it, 'at the centre of all the protest movements is a new sociological type: the graduate with no future' (Mason 2013: 66). This 'sociological type' is often both transnational and has some characteristics of a class:

...members of this generation of 'graduates with no future' recognise one another as part of an international sub-class, with behaviours and aspirations that easily cross borders...the boom years of globalization created a mass transnational culture of being young and educated; now there is a mass transnational culture of disillusionment (2013: 69) As Mason's portrayal suggests, the protesters are typically cosmopolitan types, who may move and study abroad, are at ease with global culture and travel, and are transnational in orientation, not least through the extensive use of social media. Many have experienced migration personally or are encompassed into transnational living by virtue of relatives and close friends who have migrated. Applying the analysis presented above, in Bourdieu's terms they score well on endowments of social and cultural capital, but are less well-placed in terms of economic capital, while with regard to Castoriadis' power hierarchy they are at the order-taking rather than order-giving end of the scale, since their lives and livelihoods are shaped by others.

In some ways such people are part of the global 'precariat', a notion recently popularised by Standing (2011). Generated by three decades of neoliberal globalisation, and considered part of a flexible labour force by employers, the precariat for Standing comprises those whose lives and identities are out of joint, and who are unable to live and pursue livelihoods in coherent and sustainable ways. Both would-be and actual migrants can be seen as part of the global 'precariat'. They are often educated but insecure in terms of livelihood and living. Migration is often seen as and can be -- a means of moving out of the precariat, but migrants often find themselves immersed in it in host countries, experiencing insecurity in life and livelihoods. In effect they move out of one section of the global precariat in their homeland to another part in host countries, sometimes indefinitely. Transnational practices by migrants or the diaspora can be seen as a way of overcoming or ameliorating precariousness in both the home and host country. 
A more sanguine perspective on the emergence of the protesters is to see them as part of the shift in the global political economy -- the so-called 'expanding middle' (Wilson and Dragusanu 2008, Kharas 2010), by which is meant both the rise of middle income countries and connected phenomenon of the 'exploding middle class', as a result of the success of globalisation. It is no coincidence that protests have erupted in many of the so-called 'emerging' countries identified by the free market proponents of globalisation (EIU 2013). As well as featuring rising prosperity, though, they are societies subject to deep division, tension and grievance driven in large part by poor and often corrupt governance. Born of both rising prosperity and affluence on one hand and of increasing disaffection and insecurity on the other, expectations and aspirations are raised among some of this group that are neither the poor nor part of the rich elite. This leads some to want to migrate to better themselves or to escape insecurity, and others to stay to press for better living conditions and a more free life at home. In the face of challenging circumstances there are choices within constraints whether to move or stay put.

Under what conditions do such people embrace migration or press for change in the circumstances in which they find themselves in their home countries? Can they be said to constitute a 'class in itself'? And to what extent can such activity -- migration and/or resistance -- be regarded as an expression of 'class for itself'?

The conventional way of presenting the alternatives to difficult conditions has been the exit/voice/loyalty triumvirate proposed long ago by Hirschman (1970). According to him, the pressure of discontentment leads to the two active options, leaving (exit) or articulating grievances in order to try to resolve them (voice). Loyalty or acquiescence was Hirschman's third, more passive option. Put more simply as 'fight or flight', his scheme amounts to the choice, in the face of adverse or dangerous conditions, between protest and resistance on one hand and moving away from adversity on the other. Developing Hirschman's ideas, Pedraza (2013) has suggested a useful framework in which she identifies four possible permutations of exit and voice, modified here with due credit to her:

- Exit impedes voice: exit weakens civil society by depriving it of motivated and energetic people who can articulate grievances

- Exit augments voice: those who leave strengthen civil society in the communities they leave behind by sending resources and ideas while away, or by bringing back resources, ideas and organisational techniques on return 
- Exit becomes voice: those in exile or in diaspora articulate the grievances of those remaining at home who cannot express discontent because of repression and fear

- Exit and voice grow together: exit and voice work in tandem, reinforcing one another.

We can see several of these permutations working in recent global protest. But the much-vaunted growth of social media (Castells 2013, Mason 2013) have made much easier the fourth permutation of exit and voice working in tandem. Transnational resources can be drawn upon to strengthen protest and resistance. During the recent wave of protest use was made of transnational connections partly forged by migration - the protesters' own or that of those they were close to. Thus both those who leave and those who stay - frequently drawn from the same class background - could contribute to the pressure for change at home.

The groups articulating such protest or undertaking migration - the voice and exit options - have some features of classes as conceived in this article. It is not being claimed that those who migrate constitute a class; however the claim can be made that migrants come from socio-economic groups that have some features of classes, as discussed in this article. Further, it is suggested that migration by members of such groups - essentially a series of private acts, though with public consequences may be seen as an expression of 'class in itself'. The act of protest - by those who remain in the homeland as well as by those who migrate and support such protest from afar - can be seen as an expression of 'class for itself'.

In short, I am suggesting that we may identify a class of potential migrants with a similar range of 'capitals' in the sense Bourdieu proposed, and in a similar position on the social hierarchy in the Castoriadis sense. Some of these do migrate to better their lives, while others, who may be connected with friends and relatives who have migrated, opt to stay in their homelands to press for change there. In the bigger picture of migration and class, we need to consider both those who leave and those who stay in conjunction with one another. The notion of common experience and common interests engendering a collective bond or connection is the key point here. When such connections are acted upon through exit and/or voice, the intersection between mobility, transnational living and 'class for itself' is manifested.

\section{Conclusion}

In this article I have argued that class, for long a key concept in social science, has been underplayed in migration studies in recent years. While dimensions of class or socio-economic difference have been considered to some degree with respect to what happens after migration (for example, social 
mobility in the second generation), this is much less the case with regard to the migration process itself and in particular the relationship between mobility and immobility - who is able to move and to where. More broadly, consideration of the material conditions that shape socio-economic standing has tended to be eclipsed by concern with socio-cultural factors that shape identity in the migration field. The article suggests that reconsideration of the ways in which social science has addressed socio-economic difference is needed to understand how migration works. I have suggested that considering class in terms of authority relations and different endowments of capital may be helpful for such understanding - not least the fungible character of class in the context of migration. Thinking about class in such ways helps us to understand who is able to move and who cannot, and the hierarchy of destinations that different migrants are able to reach, particularly given an increasingly stringent international migration regime. Such concerns are reflected to some degree in the debates about the relationship between mobility and immobility that have figured in some of the migration and mobilities literatures in recent years. The notion of class involves not just socio-economic position, or 'class in itself', but the idea of collective action by those with similar interests - 'class for itself'. The recent rise of global protest arguably manifests such collective action and illustrates ways in which class, migration and transnational living can intersect, as some move to better their lives while others stay put and press for change at home, against the background of both rising prosperity and increasing social conflict worldwide. This article has attempted to show how these different dimensions of 'class in itself' and 'class for itself' unfold in the migration field, underscoring the dynamic character of the interplay between migration and class, and their place in wider currents of social change.

I certainly do not claim to have resolved definitively the issue of the interplay between migration and class in this article. Nor is it claimed that class trumps other considerations - such as policy for example - in shaping migration. The more modest aim has been to reinstate consideration of how class or socio-economic difference plays out in the political economy of migration and some of its consequences. In pursuit of that objective, the focus on material dimensions of social relations that shaped earlier considerations of class needs to be folded together with the notions of culture and identity that have figured in more recent analysis of social difference. 


\section{Acknowledgments}

This article revisits and refines some of the arguments of an earlier paper developed around a decade ago (Van Hear 2004, 2006). Sketches of the current article were presented at the 'Mobilities:Immobilities' workshop held at the Christian Michelsen Institute in Bergen and at the THEMIS (Theorising the Evolution of European Migration Systems) conference hosted by the International Migration Institute in Oxford, both in September 2013. I am grateful to participants at both events, particularly Cathrine Brun, Jennifer Hyndman and Steve Lubkemann, as well as to the editors of this volume for their critical comments. I am also grateful to colleagues at COMPAS and at the Oxford Diasporas Programme funded by the Leverhulme Trust, and to Canada's International Development Research Centre for support while developing the ideas in this article.

\section{References}

Andrew, E. 1983. 'Class in itself and class against capital: Karl Marx and his classifiers', Canadian Journal of Political Science, 16, 3, 577-584.

Bottero, W. (2004) 'Class identities and the identity of class', Sociology, 38, 5, 985-1003.

Bourdieu, P. 1986. The forms of capital, in Handbook of theory and research for the sociology of education. Ed J Richardson. New York: Greenwood Press.

Bourdieu, P. 1987. 'What makes a social class? On the theoretical and practical existence of groups', Berkeley Journal of Sociology, 32, 1-17.

Bourdieu, P and Wacquant, L. 1992. An invitation to reflexive sociology. Cambridge: Polity.

Card, David, and Steven Raphael (eds) (2013) Immigration, Poverty and Socioeconomic Inequality. New York: Russell Sage Foundation.

Carling, J 2002. 'Migration in the age of involuntary immobility: Theoretical reflections and Cape Verdean experiences', Journal of Ethnic and Migration Studies, 28, 1: 5-42

Castells, M. 2013 Networks of Outrage and Hope: Social Movements in the Internet Age Cambridge: Polity Press.

Castles, S 2010 'Understanding global migration: a social transformation approach', Journal of Ethnic and Migration Studies, 36, 10: 1565-1586.

Castles, Stephen and G. Kosack (1973) Immigrant Workers and the Class Structure of Western Europe. London: Oxford University Press. 
Castoriadis, C. (Paul Cardan) 1964 Redefining revolution, London: Solidarity, translation Maurice Brinton.

Cohen, R. (1987) The new helots: migrants in the international division of labour, Aldershot: Gower.

Cohen, R. $(1997,2008)$ Global Diasporas: an Introduction, London: Routledge, $1^{\text {st }}, 2^{\text {nd }}$ edition.

Cresswell, T. 2010, 'Towards a politics of mobility' Environment and Planning D: Society and Space $28,1,17-31$

Economist Intelligence Unit (EIU) 2013 Rebels without a cause: what the upsurge in protest movements means for global politics, London: EIU.

Faist, T. 2000 The volume and dynamics of international migration and transnational social spaces. Oxford: Oxford University Press.

Franquesa, J. (2011), "We've lost our bearings": place, tourism, and the limits of the 'mobility turn', Antipode, 43: 1012-1033.

Glick Schiller, N., L. Basch, and C. Szanton Blanc (1992), 'Transnationalism: a new analytic framework for understanding migration', Annals of the New York Academy of Sciences, 645, 1-24.

Guarnizo, L. (2003) 'The economics of transnational living', International Migration Review 37, 3.

Graeber, D. 2013 The Democracy Project: A History, a Crisis, a Movement, New York: Random House.

Hammar, T., Brochmann G., Tamas, K. and Faist, T. 1997, International migration, immobility and development, Oxford: Berg.

Harvey, D. (1989) The Condition of Postmodernity, London: Blackwell.

Hirschman, A, 1970. Exit, voice and loyalty: responses to decline in firms, organisations and states Cambridge MA: Harvard University Press.

Hyndman, J. 2000 Managing displacement: refugees and the politics of humanitarianism. Minneapolis: University of Minnesota Press.

Kharas, H. 2010. The emerging middleclass in developing countries. OECD Development Centre working paper 285.

King, R 2012 Theories and typologies of migration: an overview and a primer, Willy Brandt Working Paper 3/12 in International Migration and Ethnic Relations, Malmo: Malmo University.

Levitt, P. and N. Glick Schiller 2004 'Conceptualizing simultaneity: a transnational social field perspective on society', International Migration Review, 38, 3: 828-1302.

Malkii, L 1992 'National Geographic: The Rooting of Peoples and the Territorialization of National Identity among Scholars and Refugees', Cultural Anthropology, 7, 1: 24-44. 
Mason, P. 2013 Why It's Still Kicking Off Everywhere, London: Verso.

Massey, Doreen. 1993 'Power-geometry and a progressive sense of place' in Jon Bird, B Curtis, T Putnam, G Robertson and L Tuckner eds Mapping the futures: local cultures, global change. London: Routledge: 59-69.

Massey, Douglas, Arango, J., Hugo, G., Kouaouci, A., Pellegrino, A., and Taylor, J., (1993) 'Theories of International Migration: A Review and Appraisal', Population and Development Review, 19, 3, 431466.

Massey, Douglas, J. Arango, G. Hugo, A. Kouaouci, A. Pellegrino, and J. E. Taylor (1998) Worlds in motion: understanding international migration at the end of the millennium, Oxford: Clarendon Press.

Mazzucato, M., Kabki, M. and Smith, L. (2006) Transnational migration and the economy of funerals: changing practices in Ghana', Development and Change, 37, 5, 1047-72.

Oliver, C. and O'Reilly, K. (2010) 'A Bourdieusian analysis of class and migration: habitus and the individualising process', Sociology, 44, 1 49-66.

Orrenius, P. and Zavodny, M. (2005) 'Self-selection among undocumented immigrants from Mexico', Journal of Development Economics 78, 215-240.

Pedraza, S. (2013) 'Social protest and migration' in The Encyclopedia of Global Human Migration, Wiley.

Pero, D. (2014) 'Class politics and migrants: collective action among new migrant workers in Britain', Sociology doi: 10.1177/0038038514523519

Portes, A. (2010) Migration and social change: some conceptual reflections, Journal of Ethnic and Migration Studies 36, 10: 1537-1564.

Portes, A., L. Guarnizo and P. Landholt (1999) 'The study of transnationalism: promises and pitfalls of an emergent research field', Ethnic and Racial Studies 22, 2: 217-237.

Savage, M., F. Devine, N. Cunningham, M. Taylor, Yaojun L., J. Hjellbrekke, B. Le Roux, S. Friedman and A. Miles (2013) 'A new model of social class: findings from the BBC's Great British Class experiment', Sociology, 47(2): 219-250.

Sheller M and Urry J, 2006, 'The new mobilities paradigm,' Environment and Planning A, 38, 2: 207 226

Standing, G. 2011 The Precariat: The New Dangerous Class, Bloomsbury.

Stark, O. (1991) The migration of labor, Oxford: Blackwell.

Urry, J. 2000 Sociology beyond societies, Cambridge: Polity. 
Urry, J. 2007 Mobilities, Cambridge: Polity

Van Hear, N. 1998 New diasporas: the mass exodus, dispersal and regrouping of migrant communities, London: University College London Press.

Van Hear, N. 2004 'I went as far as my money would take me': conflict, forced migration and class. Centre on Migration, Policy and Society (COMPAS), Working Paper 6, 2004, Oxford: COMPAS. Later published in F Crepeau et al eds. 2006, Forced migration and global processes: a view from forced migration studies, Lanham MA: Lexington/Rowman and Littlefield: 125-158.

Van Hear, N. 2013 'Flight and fight', COMPAS blog, compasoxfordblog.co.uk/2013/10/flight-andfight/

Wacquant L. 2013 'Symbolic power and group-making: on Pierre Bourdieu's reframing of class' Journal of Classical Sociology May 2013 13, 2: 274-291.

Wilson, D. and R. Dragusanu (2008). The expanding middle: the exploding world middle class and falling global inequality, Goldman Sachs, Global Economic Paper 70. 